\title{
Management of a Giant Omphalocele with Non- Cross-Linked Intact Porcine-Derived Acellular Dermal Matrix (Strattice) Combined with Vacuum Therapy
}

\author{
Daisy Vieira Travassos ${ }^{1} \quad$ Albertien M. van Eerde ${ }^{2} \quad$ William L.M. Kramer ${ }^{1}$ \\ ${ }^{1}$ Department of Pediatric Surgery, Wilhelmina Children's Hospital, \\ University Medical Center Utrecht, The Netherlands \\ 2 Department of Medical Genetics, University Medical Center Utrecht, \\ The Netherlands \\ Address for correspondence Daisy Vieira Travassos, Department of \\ Pediatric Surgery, KE 04.140.5, University Medical Center Utrecht, \\ Wilhelmina Children's Hospital, P.O. Box 85090, 3508 AB Utrecht, The \\ Netherlands (e-mail: d.vieira-travassos@umcutrecht.nl).
}

Eur J Pediatr Surg Rep 2015;3:61-63.

\begin{abstract}
Keywords

- omphalocele

- Strattice

- acellular dermal matrix

The management of giant omphaloceles at our department is primarily conservative. However, management can be challenging if the omphalocele is ruptured or the sac has to be removed. We report a case in which a giant omphalocele in a newborn female patient was managed by covering the abdominal defect with non-cross-linked intact porcine-derived acellular dermal matrix (Strattice reconstructive tissue matrix, LifeCell Corp., Branchburg, New Jersey, United States) sutured to the fascia combined with vacuum therapy.
\end{abstract}

\section{New Insights and the Importance for the Pediatric Surgeon}

The management of giant omphaloceles is mostly conservative. However, management can be challenging if the omphalocele is ruptured or the sac has to be removed. We present PADM with vacuum therapy as a good alternative in the treatment of giant complicated omphaloceles.

\section{Introduction}

An otherwise healthy mother had a routine ultrasound at 20 weeks, which showed giant omphalocele with liver included in the omphalocele sac. Karyotyping of the amniotic fluid cells showed a normal female karyotype (46, XX), $\alpha-$ fetoprotein (AFP) in amniotic fluid was raised ( $38.7 \mathrm{mg} / \mathrm{L} ; 3 \times$ $\mathrm{MoM}=20.1 \mathrm{mg} / \mathrm{L}$ ).These findings were discussed with the parents and it was decided to continue the pregnancy.

The baby was born at 38 weeks and 2 days of gestation by elective cesarean delivery. The birth weight was $3,500 \mathrm{~g}$ and Apgar scores were $8 / 9$ at 1 and 5 minutes, respectively.

The omphalocele contained a big part of the liver, almost the whole bowel, and the spleen. The baby had no further anomalies or evident dysmorphisms. Immediately after birth, the omphalocele was covered with a sterile petrolatum
(Vaseline, Smith \& Nephew, Kruisweg, Hoofddorp, Netherlands) gauze dressing, which was changed every other day. The baby expelled meconium shortly after birth and also upon arrival in the neonatal intensive care unit. Feeding was started via nasogastric tube and was well tolerated during the first days of life. On the 6 th day after birth, the baby developed a bowel obstruction and underwent corrective surgery. During the operation, we resected the omphalocele sac (which was vulnerable by manipulation) and performed adhesiolysis to appropriately position the spleen and bowel in the abdominal cavity. The liver remained outside the abdominal cavity.

A Silo bag (SB06, 60-mm; Medicina Ltd., Bolton, United Kingdom) was used to temporarily cover the defect and central venous access was obtained in the left subclavian vein (-Supplementary Fig. $\mathbf{S 1}$ in the online version of the received

June 4, 2014

accepted after revision

March 2, 2015

published online

June 26, 2015
DOI http://dx.doi.org/

$10.1055 / s-0035-1549364$. ISSN 2194-7619.
@ 2016 Georg Thieme Verlag KG
Stuttgart · New York

License terms

(1) $\Theta \circledast$ 


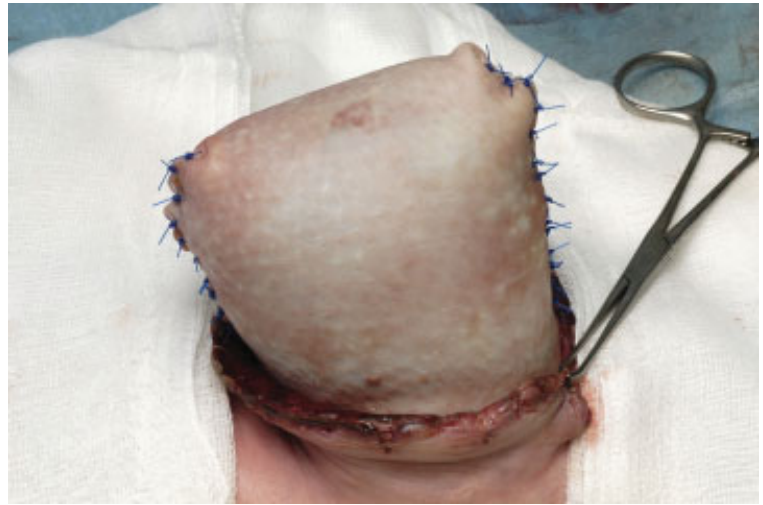

Fig. 1 Completed suturing of the fascia to the porcine-derived acellular dermal matrix (14th day after birth).

article). The biggest Silo bag available (60-mm) was not big enough to accommodate the liver and was therefore enlarged by attaching a triangular patch made of silastic mesh. Because the use of a Silo is not optimal for treatment when the liver is situated outside the abdominal cavity, alternative treatment approaches had to be considered. On the 14th day after birth, we removed the Silo and placed non-cross-linked intact porcine-derived acellular dermal matrix (PADM; Strattice reconstructive tissue matrix, LifeCell Corp., Branchburg, New Jersey, United States) at the fascia and sutured it with Prolene 3-0 sutures (Ethicon, Somerville, New Jersey, United States) ( - Fig. 1). A vacuum dressing system was used to cover the PADM with a negative pressure of $-75 \mathrm{~mm} \mathrm{Hg}$ (- Supplementary Fig. $\mathbf{2} 2$ in the online version of the article). The vacuum system was changed in the operation theater on postoperative days 3 (-Supplementary Fig. $\$ 3$ in the online version of the article), 9, and 12 and on the pediatric ward thereafter. Amoxicillin/potassium clavulanate and gentamicin were initiated for prophylaxis against infection and then changed to meropenem. Wound cultures were obtained periodically and remained negative. The PADM showed no signs of infection during this time (- Supplementary Fig. 54 in the online version of the article).

On the 26th day of life, the patient developed sepsis from the central venous catheter infection. Central venous system blood cultures were positive and the patient experienced nephritis and renal insufficiency that subsided spontaneously. We started minimal enteral feeding 2 days after implantation of the PADM. The feeding was well tolerated and defecation was facilitated by daily rectal washout. Enteral feeding was suspended during the sepsis; however, the patient was tolerating full enteral nutrition by 45 days postnatal age.

On the 41st day of life the result of the postnatal array-CGH (Agilent Technologies, Santa Clara, California, United States) was returned, it showed a maternally inherited $780 \mathrm{~kb}$ deletion on chromosome band 3q28 containing part of the TP63 gene, and four more genes that cause autosomal recessive syndromes.

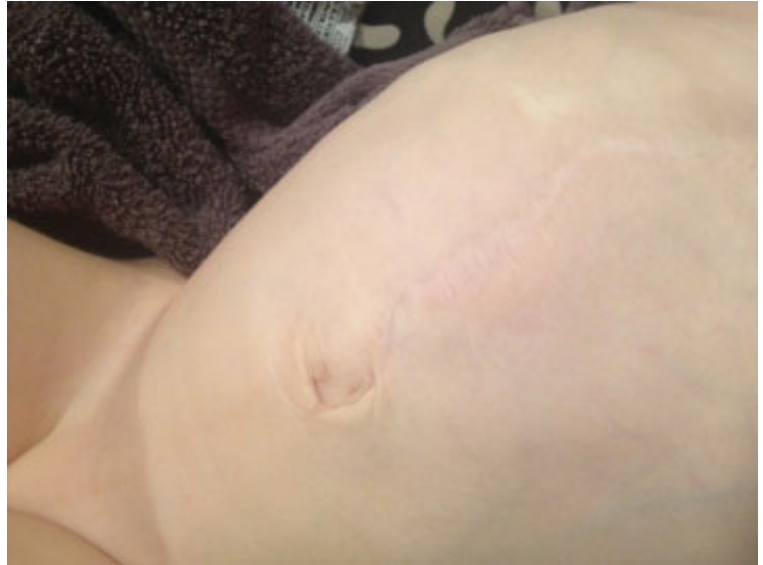

Fig. 2 Cosmetic result after 6 months of the abdominal wall reconstruction.

The patient was discharged home at age 2 months and 10 days with the vacuum therapy, which was discontinued 1 week later. After removing the vacuum therapy, the patient was bathed daily by her parents and had a sterile petrolatum gauze dressing in place until the wound closed completely (- Supplementary Fig. S5 in the online version of the article).

Ventral hernia repair was performed when the patient was 2 years and 3 months old (-Supplementary Fig. $\mathbf{S 6}$ in the online version of the article). The PADM had become integrated into the surrounding fascia and was used to close the abdominal wall (-supplementary Fig. 57 in the online version of the article). A sample of this PADM taken during ventral hernia repair was sent for histological examination.

The patient did well postoperatively (-supplementary Fig. $\mathbf{5 8}$ in the online version of the article) and experienced no complications through 6 months of follow-up (-Fig. 2).

\section{Discussion}

Omphaloceles are often associated with other malformations and chromosomal anomalies., ${ }^{1,2}$ The small chromosome 3 deletion in this case (1) is to our best knowledge (based on queries in PubMed database and Decipher database) not known to be associated with omphalocele, (2) contains no genes explicitly associated with omphalocele, ${ }^{3}$ and (3) was inherited from a healthy mother. ${ }^{4}$ Therefore, this deletion was considered to be most likely of neutral effect. The raised amniotic fluid AFP was associated with the omphalocele. ${ }^{5}$

Giant omphaloceles are not common, which makes it difficult for a single pediatric surgery department to gain extensive treatment experience. Furthermore, most of the very large omphaloceles can be treated conservatively with sterile petrolatum dressing until the epithelialization of the defect results in a large ventral hernia that can be subsequently closed when there is adequate space in the abdominal cavity. In cases where the omphalocele sac has to be removed 
or when a rupture occurs, the pediatric surgeon can face surgical challenges.

The use of a combination of a biological matrix graft and vacuum therapy for treating abdominal wall defects has been previously reported in the medical literature ${ }^{6-8}$; however, the use of PADM for this purpose has not yet been described in our knowledge.

Strattice is a non-cross-linked porcine, acellular dermal matrix for use in xenograft transplantation, serving as a biological scaffold to support tissue regeneration. ${ }^{9,10}$ It is derived from porcine dermis and processed in a manner to remove the cells and porcine antigens which would provoke an immune response in humans, while retaining all its extracellular matrix (ECM) components, its three-dimensional structure and its biomechanical strength. As such when implanted, it acts as a scaffold to support tissue ingrowth. Its ECM components attract in cells and vascularity from the patients adjacent tissue, and over time it is replaced by the patients' own tissue with all components of the porcine matrix removed, in a regenerative tissue healing process. ${ }^{11,12}$

In this patient, the use of PADM was successful and showed good long-term biological compatibility, as the histological examination of the collagen showed no difference with the human collagen 2 years after suturing the patch to the fascia (-Supplementary Fig. 59 in the online version of the article). The microscopic examination showed dissections of tissue fragments, irregular collagen bundles containing numerous small vessels, and signs of very mild chronic infection. Based on the histology examination, it was not possible to determine if the sample consisted of porcine collagen tissue or human collagen, even after applying Sirius red and Verhoeff-Van Gieson staining.

The PADM became integrated with the fascia and was strong enough to be partially used to strengthen closure of the abdominal wall defect.

\section{Conclusion}

PADM with vacuum therapy is a good alternative in the treatment of giant omphaloceles.

\section{Acknowledgments}

Editorial support for this article was provided by Peloton Advantage, LLC, Parsippany, New Jersey, United States, and funded by LifeCell Corp., Branchburg, New Jersey, United States. The opinions expressed in this article are those of the authors. The authors received no honoraria/fee for service or other form of financial support related to the development of this article. The authors declare no conflicts of interest.

\section{References}

1 Hurst J, Firth HV, Chitty LS. Syndromic associations with congenital anomalies of the fetal thorax and abdomen. Prenat Diagn 2008; 28(7):676-684

2 Porter A, Benson CB, Hawley P, Wilkins-Haug L. Outcome of fetuses with a prenatal ultrasound diagnosis of isolated omphalocele. Prenat Diagn 2009;29(7):668-673

3 Brunner HG, Hamel BC, Bokhoven Hv Hv. P63 gene mutations and human developmental syndromes. Am J Med Genet 2002;112(3): 284-290

4 Firth HV, Richards SM, Bevan AP, et al. DECIPHER: Database of chromosomal imbalance and phenotype in humans using ensembl resources. Am J Hum Genet 2009;84(4):524-533

5 Saller DN Jr, Canick JA, Palomaki GE, Knight GJ, Haddow JE. Secondtrimester maternal serum alpha-fetoprotein, unconjugated estriol, and hCG levels in pregnancies with ventral wall defects. Obstet Gynecol 1994;84(5):852-855

6 Gabriel A, Gollin G. Management of complicated gastroschisis with porcine small intestinal submucosa and negative pressure wound therapy. J Pediatr Surg 2006;41(11):1836-1840

7 Kilbride KE, Cooney DR, Custer MD. Vacuum-assisted closure: a new method for treating patients with giant omphalocele. J Pediatr Surg 2006;41(1):212-215

8 Wilcinski SL. Use of a vacuum-assisted device in a neonate with a giant omphalocele. Adv Neonatal Care 2010;10(3):119-126, quiz 127-128

9 Campbell KT, Burns NK, Rios CN, Mathur AB, Butler CE. Human versus non-cross-linked porcine acellular dermal matrix used for ventral hernia repair: comparison of in vivo fibrovascular remodeling and mechanical repair strength. Plast Reconstr Surg 2011; 127(6):2321-2332

10 Byrd JF Jr, Agee N, Getz SB, Lincourt AE, Iannitti DA, Heniford BT. Evaluation of porcine-derived grafts (XenMatrix, Strattice, and Permacol) in an in vivo preclinical study [abstract]. In: Proceedings of the 90th Annual Meeting of the American Association of Plastic Surgeons; April 9-12, 2011; Boca Raton, FL

11 Connor J, McQuillan D, Sandor M, et al. Retention of structural and biochemical integrity in a biological mesh supports tissue remodeling in a primate abdominal wall model. Regen Med 2009;4(2): 185-195

12 Sandor M, Xu H, Connor J, et al. Host response to implanted porcine-derived biological materials in a primate model of abdominal wall repair. Tissue Eng Part A 2008;14(12):2021-2031 